\title{
Variation characteristics of coal-rock mechanical properties under varying temperature conditions for Shanxi Linfen coalbed methane well in China
}

\author{
Xin $\mathrm{Li}^{1,2} \cdot$ Jie Zhang ${ }^{1,2} \mathbb{D} \cdot$ Cuinan $\mathrm{Li}^{3} \cdot$ Ben $\mathrm{Li}^{4} \cdot$ Haoyang Zhao ${ }^{5} \cdot$ Rongxin $\mathrm{Li}^{1,2} \cdot \mathrm{Qi} \mathrm{Qi}^{1,2}$
}

Received: 10 March 2021 / Accepted: 7 May 2021 / Published online: 30 May 2021

(c) The Author(s) 2021

\begin{abstract}
In the actual exploitation process of coalbed methane (CBM), as the fluid in the wellbore continues to circulate, the surrounding rock of the CBM well will continuously exchange heat with the fluid in the wellbore, resulting in continuous changes in the temperature of the surrounding rock itself. Linfen, Shanxi is the main exploitation area for CBM in China. This paper aims further to improve the exploitation efficiency of CBM in this area and conducts experimental research on the change characteristics of coal-rock mechanical properties under varying temperature conditions. The experimental results show that under constant pressure conditions, the higher the temperature, the lower the stress value when the coal-rock breaks. In the process of reaching peak strength, the higher the temperature, the higher the proportion of coal-rock plastic deformation in its entire deformation stage. The compressive strength, elastic modulus, and main crack length of coal-rock will decrease with temperature. The Poisson's ratio and primary fracture angle will increase with the increase of experimental temperature.
\end{abstract}

Keywords CBM $\cdot$ Temperature $\cdot$ Coal-rock $\cdot$ Mechanical properties $\cdot$ Experimental research

\section{Introduction}

According to the data in the "Special Evaluation of China's Coalbed Methane Resource Dynamics" report, at the end of 2018, the cumulative demonstrated geological reserves of CBM in Shanxi Province was $5.81 \times 10^{11} \mathrm{~m}^{3}$, accounting for $89.2 \%$ of China's demonstrated reserves. In the past five

Jie Zhang

swpivip@163.com

1 State Key Laboratory of Oil and Gas Reservoir Geology and Exploitation, Southwest Petroleum University, Chengdu 610500, Sichuan, People's Republic of China

2 Petroleum Engineering School, Southwest Petroleum University, Chengdu 610500, Sichuan, People's Republic of China

3 Engineering Technology Research Institute, CNPC Southwest Oil and Gasfield Company, Guanghan 618300, Sichuan, People's Republic of China

4 Exploration Department, CNPC Huabei Oilfield Company, Renqiu 062550, Hebei, People's Republic of China

5 Engineering Technology Research Institute, CNPC Coalbed Methane Co., Ltd, Beijing 100028,

People's Republic of China years, newly-added demonstrated reserves have gradually decreased, and the growth of cumulative demonstrated geological reserves has slowed down and has shown a downward trend. In 2016, the cumulative demonstrated geological reserves reached the maximum value of $6.12 \times 10^{11} \mathrm{~m}^{3}$. Figure 1 shows the growth trend of CBM reserves in Shanxi Province from 2008 to 2018 (Wang et al. 2020). Linfen is currently the coalfield with the highest demonstrated reserves in Shanxi Province. At the end of 2018, the cumulative demonstrated reserves were $4.35 \times 10^{11} \mathrm{~m}^{3}$, accounting for $74.8 \%$ of China's demonstrated reserves. At present, the exploitation depth of CBM in Linfen is mostly coal seams above $800 \mathrm{~m}$. With the continuous exploitation of shallow resources, the future exploitation trend gradually expands to deeper coal seams. Deep coal seams are in a geological environment of high formation temperature, high crustal stress, high reservoir pressure, and low permeability, which is very different from shallow coal seams.

As the depth of CBM exploitation gradually deepens, the formation temperature will become higher and higher, and the circulation time of the fluid in the wellbore will become longer and longer. During the circulation process, the wellbore fluid will exchange heat with the surrounding rock through convective heat exchange and heat conduction 
Fig. 1 The growth trend of CBM reserves in Shanxi Province from 2008 to 2018

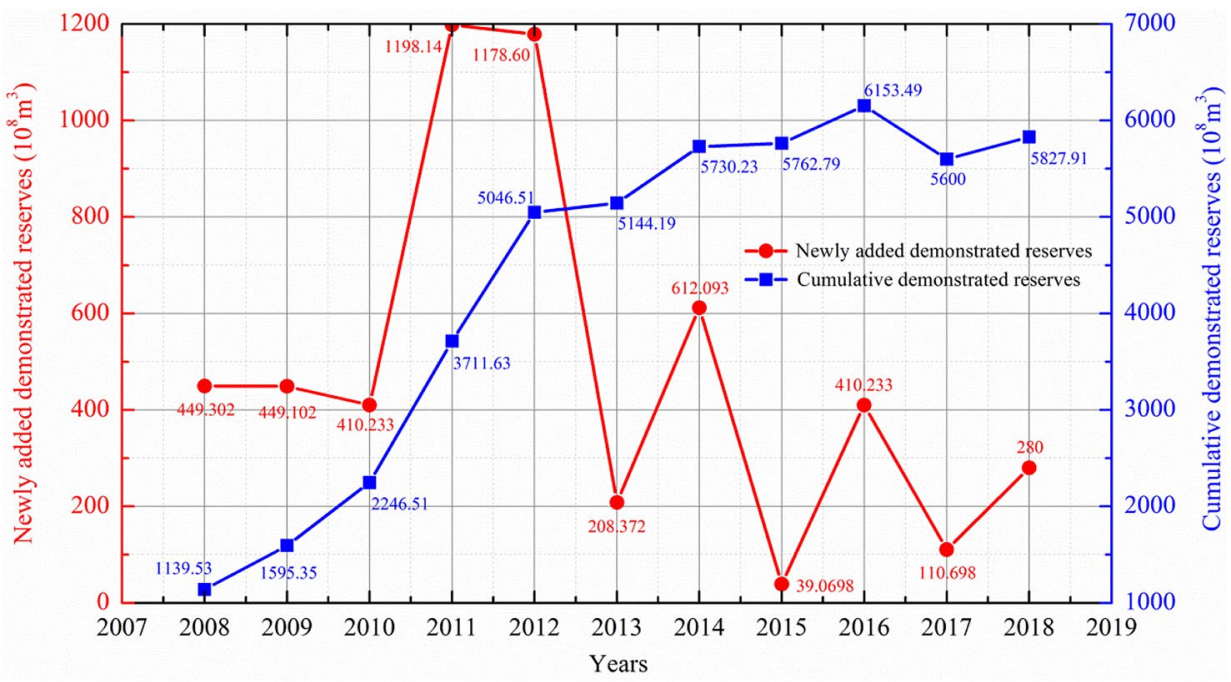

(Zhang et al. 2019; Li et al. 2020). The surrounding rock is affected by the effect of thermal expansion and contraction, and its mechanical properties will inevitably change, which will have a specific impact on the exploitation process.

Many scholars in the world have carried out related research work in response to the problem of changes in sandstone properties caused by temperature changes. Rao et al. (2007) used the Brazilian disc experiment, axial compression experiment, and three-point bending experiment to determine the change characteristics of sandstone's tensile strength, uniaxial compression strength, elastic modulus, and fracture toughness under high-temperature conditions. The experiment results show that at $200{ }^{\circ} \mathrm{C}$ or $250{ }^{\circ} \mathrm{C}$, the above-mentioned mechanical properties of sandstone will increase with temperature. Still, when the temperature exceeds this temperature, these mechanical properties will decrease with the temperature rise. Ranjith et al. (2012), to explore the mechanical response of sandstone to significant temperature changes, conducted uniaxial compressive strength tests on sandstone at different temperatures between $25^{\circ} \mathrm{C}$ and $950{ }^{\circ} \mathrm{C}$. The experimental results show that the compressive strength and elastic modulus of sandstone are related to temperature. When the temperature is lower than $500{ }^{\circ} \mathrm{C}$, the sandstone's compressive strength and elastic modulus will increase. Still, when the temperature is higher than $500{ }^{\circ} \mathrm{C}$, they will decrease with temperature. Sirdesai et al. (2017) designed two sets of experiments to test the change characteristics of the tensile strength of sandstone under different temperature conditions. One group of sandstone samples were tested directly after heat treatment without any cooling. The cooling time of the other experiment was the same as the heat treatment time. The experiment results show that the tensile strength of the rock will increase in a specific temperature range, and then the tensile strength will decrease. Shen et al. (2018) conducted experimental tests on the change of the microstructure of sandstone with temperature. The experimental results show that the quartz component in sandstone undergoes a phase transition from $\alpha$ - to $\beta$ - in the temperature range of $400{ }^{\circ} \mathrm{C}$ to $600{ }^{\circ} \mathrm{C}$. The lattice constant, micro-strain, dislocation density, and TGA curve of sandstone decrease sharply, resulting in microstructure has deterioration. The calcite component in sandstone undergoes a decomposition reaction between $600{ }^{\circ} \mathrm{C}$ and $800^{\circ} \mathrm{C}$, which causes the lattice constant, micro-strain, and TGA curve to continue to decline and further leads to the destruction of the internal microstructure of the sandstone. Mahanta et al. (2020) used acoustic emission and image correlation through ARAMIS to study the mechanical response of sandstone with increasing temperature. The research results show that the uniaxial compressive strength, tensile strength, and elastic modulus of sandstone will decrease significantly with temperature. They obtained the maximum and minimum uniaxial compressive strength of sandstone at $400{ }^{\circ} \mathrm{C}$ and $700{ }^{\circ} \mathrm{C}$, respectively. The acoustic emission response of sandstone after high-temperature treatment indicates early crack initiation and crack damage. They used the image correlation through ARAMIS to visually quantify the strain level of the sample after $700{ }^{\circ} \mathrm{C}$ heat treatment, and the result showed a wide range of high strain distribution. Tripathi et al. (2021) found through experimental tests that the crack density, porosity, and thermal damage of sandstone increase rapidly with temperature in the range of $300-500{ }^{\circ} \mathrm{C}$. The seismic wave velocity, uniaxial compressive strength, tensile strength, and elastic parameters decrease sharply with the increase of temperature.

In addition to the study of sandstone, many scholars worldwide have also carried out corresponding research work on the characteristics of coal-rock properties that change with temperature. Jiang et al. (1997) conducted an experimental analysis on the stress-strain curve of coal-rock 
under different temperature and pressure conditions. The research results found that in the medium deformation stage, the increase in confining pressure can increase coal's strength to a certain extent. However, the effect of temperature is more critical. In the large deformation stage, the role of confining pressure rises to the dominant position. Cheng et al. (1998) discussed the influence of temperature and effective stress on the permeability coefficient of coal-rock through the coal-rock seepage experiment under variable temperature conditions. They built the regression equation of permeability coefficient and temperature, permeability coefficient, and effective stress. Ma et al. (2005) completed the experimental research on the influence of temperature on the mechanical properties of coal-rock on the MTS810 experimental system. The research results show that with the increase of temperature in the range of $25-50{ }^{\circ} \mathrm{C}$, the coal rocks' compressive strength and elastic modulus show a decreasing trend, and the strain shows an increasing trend. In the range of $50-100{ }^{\circ} \mathrm{C}$, the compressive strength, elastic modulus, and coal-rock strain show a decreasing trend. $\mathrm{Xu}$ et al. (2011) conducted experimental tests on the permeability of coal-rock under different effective stress, gas pressure, and temperature conditions. The experimental results show that when the effective stress and gas pressure remain constant, as the temperature increases, coal-rock permeability will decrease. Under the same temperature conditions, the greater the effective stress and gas pressure, the smaller the temperature's influence on coal-rock permeability. Yu et al. (2013) tested the change characteristics of coal-rock permeability under different confining pressures, axial pressures, and temperatures through the ZYS-1 triaxial permeability instrument. Experimental results show that temperature has a significant effect on gas flow in coal-rock. With the increase of temperature, the dynamic viscosity of gas increases, and the volume of solid particles in coal expands, reducing the pore space and hindering gas flow. $\mathrm{Li}$ et al. (2016) conducted an experimental study on the crack propagation law of coal-rock under cold and heat alternating action. The research results show that the alternation of cold and heat can cause further damage to the fractured structure of coal-rock, and the bearing capacity of coal-rock decreases with the depth of the damage of the fractured structure. Wei et al. (2017) studied the changing law of coal-rock permeability under temperature shock conditions and the mechanism of increasing the permeability. The research results show that the average increase of coal-rock is $48.68 \%$ and $469.24 \%$ after cold shock treatment and heat-cold shock treatment. Compared with cold shock treatment, heat-cold shock treatment produces more cracks and has a better antireflection effect. Yan et al. (2020) conducted experimental research on the surface crack propagation law and pore damage characteristics of coal-rock with different prefabrication temperatures after immersion in liquid nitrogen. During the liquid nitrogen leaching process, with the increase of the prefabrication temperature, the coal-rock surface's thermal stress increases. The increased ratio of the characteristic fracture area of the coal-rock also increases. The increase in thermal stress significantly correlates with the increase in characteristic fractures on the coal-rock surface.

Although scholars have carried out a lot of research work on temperature-induced rock property changes, the current research of the relationship between the coal-rock physical properties and temperature changes mainly focuses on temperature changes permeability of coal-rock. In addition, the temperature loaded during the experiment is too low, and the conclusions drawn cannot support the exploitation of deep CBM. Based on the above problems, we used RTR-1000 high-temperature and high-pressure rock triaxial mechanics testing system to test the mechanical properties of the coal-rock samples taken from the Linfen CBM well in Shanxi Province under variable temperature conditions. We obtained the influence law of temperature change on the stress-strain curve, axial strain, radial strain, volume strain, and various mechanical parameters of coal-rock. The conclusions obtained provide an essential theoretical basis for the exploitation of deep CBM in Linfen, Shanxi.

\section{Structural characteristics of the block}

The coal-rock samples used in the experiment are all from the wells numbered JP-1H and JP-30 in the Daning CBM exploitation area in Linfen City, Shanxi Province. The Daning block as a whole presents a basic structural pattern of "one uplift, one depression, and two slopes," namely the Taoyuan anticline belt in the middle, the Puxian depression belt, the Mingzhu slope belt in the east, and the western slope belt. Wells numbered JP-1H and JP-30 locate in the western slope zone of Daning block. The structural position of the block belongs to the eastern part of the Yishan slope in the Ordos Basin, and the overall structure is a westwarddipping slope. The well area is structured as a large, wide, gentle west-dip monoclinic, and the formation is gentle. Figures 2 and 3 show the top surface structure diagram of the $8 \#$ coal seam of the Benxi Formation for the JP-1H well and the JP-30 well.

\section{Experimental test}

\section{Experimental material}

Considering the sample diameter that the experimental equipment can hold, following the International Society of Rock Mechanics regulations, the coal-rock samples are processed into cylinders with a diameter of about $25 \mathrm{~mm}$ and

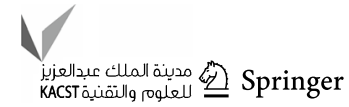


Fig. 2 The top surface structure diagram of the $8 \#$ coal seam of the Benxi Formation for the JP-1H well
Fig. 3 The top surface structure diagram of the $8 \#$ coal seam of the Benxi Formation for the JP-30 well
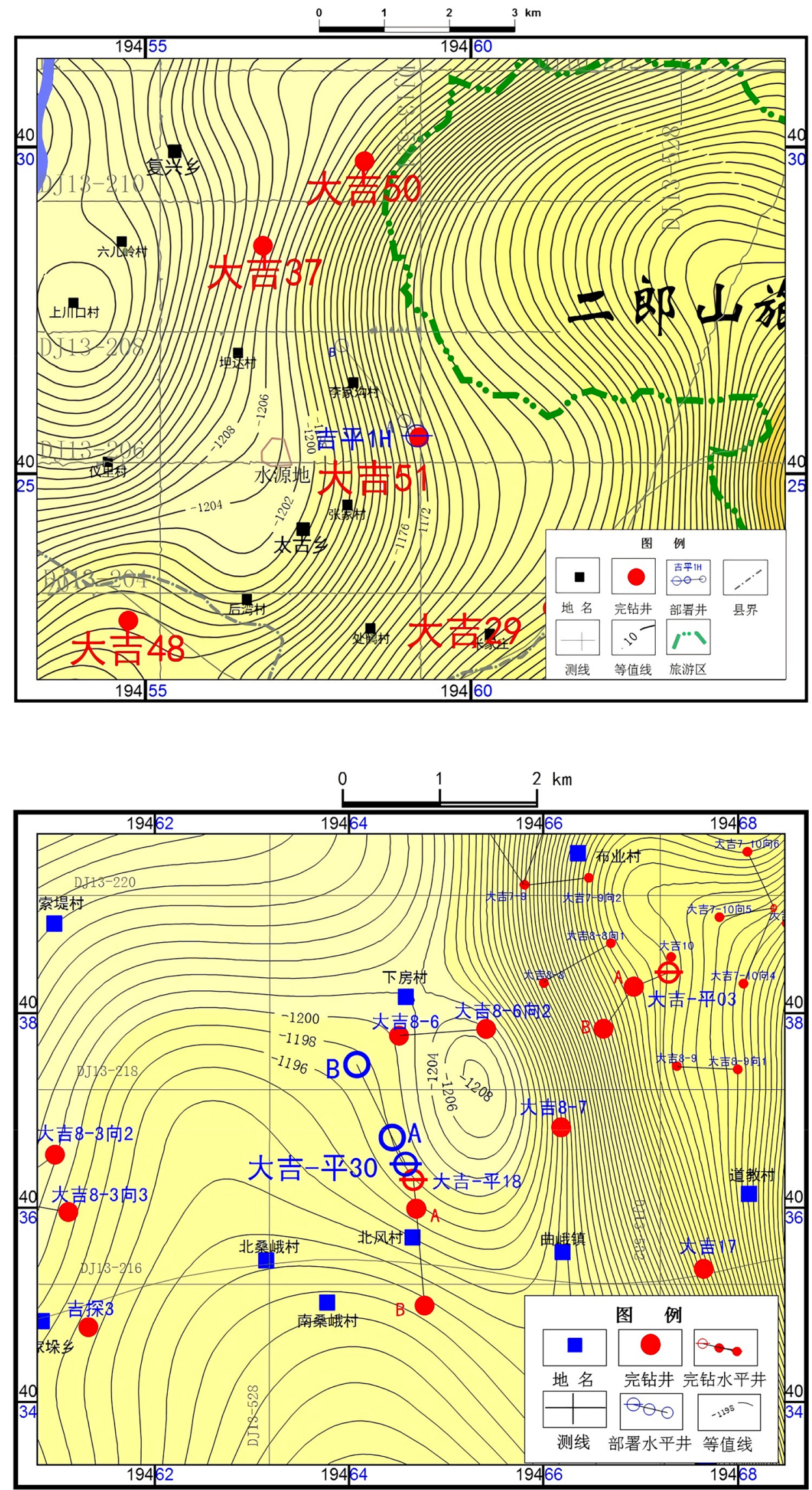
a height of about $50 \mathrm{~mm}$. The machining accuracy meets the requirement that both ends' non-parallelism error is less than $2 \mathrm{~mm}$, and the section unevenness error is less than $1 \mathrm{~mm}$. Figure 4 shows the coal-rock samples for experimental testing. The data in Table 1 is the size and weight of the processed coal-rock samples.

\section{Experimental equipment}

The equipment used in this experiment is the RTR-1000 high-temperature and high-pressure rock triaxial mechanics testing system. The testing system can produce a maximum axial pressure of $1000 \mathrm{kN}$, maximum confining pressure of $140 \mathrm{MPa}$, pore pressure of $140 \mathrm{MPa}$, dynamic frequency of $10 \mathrm{~Hz}$, the temperature of $150^{\circ} \mathrm{C}$. The experimental control accuracy is pressure $0.01 \mathrm{MPa}$, liquid volume $0.01 \mathrm{~g} / \mathrm{cm}^{3}$, deformation amount $0.001 \mathrm{~mm}$. Figure 5 shows the main component of the experimental equipment.

\section{Experimental method}

The burial depth of the coal seam simulated in this experiment is $2500 \mathrm{~m}$, the surface temperature is set to $25^{\circ} \mathrm{C}$, and the ground temperature gradient is set to $0.03{ }^{\circ} \mathrm{C} / \mathrm{m}$. Therefore, the maximum temperature of the coal seam at $2500 \mathrm{~m}$ is about $100^{\circ} \mathrm{C}$. In order to comprehensively test the change characteristics of the mechanical properties of coalrock samples with temperature, we designed a total of 5 sets of experiments, each of which was tested three times. When testing the same set of coal-rock samples, the temperature
Table 1 The size and weight of the processed coal-rock samples

\begin{tabular}{lllll}
\hline Group no & Sample no & Diameter $(\mathrm{mm})$ & Height $(\mathrm{mm})$ & Weight $(\mathrm{g})$ \\
\hline 1 & $\# 1-1$ & 25.71 & 50.61 & 42.505 \\
& $\# 1-2$ & 25.78 & 50.62 & 43.288 \\
& $\# 1-3$ & 25.84 & 50.18 & 41.354 \\
2 & $\# 2-1$ & 25.75 & 50.68 & 41.572 \\
& $\# 2-2$ & 25.76 & 50.32 & 40.608 \\
& $\# 2-3$ & 25.68 & 49.91 & 40.679 \\
3 & $\# 3-1$ & 26.02 & 50.04 & 41.806 \\
& $\# 3-2$ & 25.93 & 49.79 & 43.198 \\
& $\# 3-3$ & 25.71 & 50.82 & 40.885 \\
& $\# 4-1$ & 25.74 & 50.92 & 40.312 \\
& $\# 4-2$ & 25.65 & 50.42 & 40.867 \\
& $\# 4-3$ & 25.85 & 50.31 & 40.315 \\
5 & $\# 5-1$ & 25.78 & 50.30 & 41.288 \\
& $\# 5-2$ & 25.74 & 50.53 & 40.599 \\
& $\# 5-3$ & 25.40 & 50.12 & 40.725 \\
\hline
\end{tabular}

and pressure we load are the same. When testing different sets of coal-rock samples, we load different temperatures. However, the pressure is the same, and the axial pressure is the same as the confining pressure to limit the influencing factors to the temperature. The temperature set in this experiment is $40{ }^{\circ} \mathrm{C}, 55{ }^{\circ} \mathrm{C}, 70{ }^{\circ} \mathrm{C}, 85^{\circ} \mathrm{C}$, and $100{ }^{\circ} \mathrm{C}$, the axial unloading rate is $0.01 \mathrm{~mm} / \mathrm{s}$, the initial axial pressure is $30 \mathrm{MPa}$, the initial confining pressure is $30 \mathrm{MPa}$, and the $\mathrm{CBM}$ pressure is $3 \mathrm{MPa}$. Table 2 shows the temperature and pressure parameters used in the experiment.
Fig. 4 The coal-rock samples for experimental testing

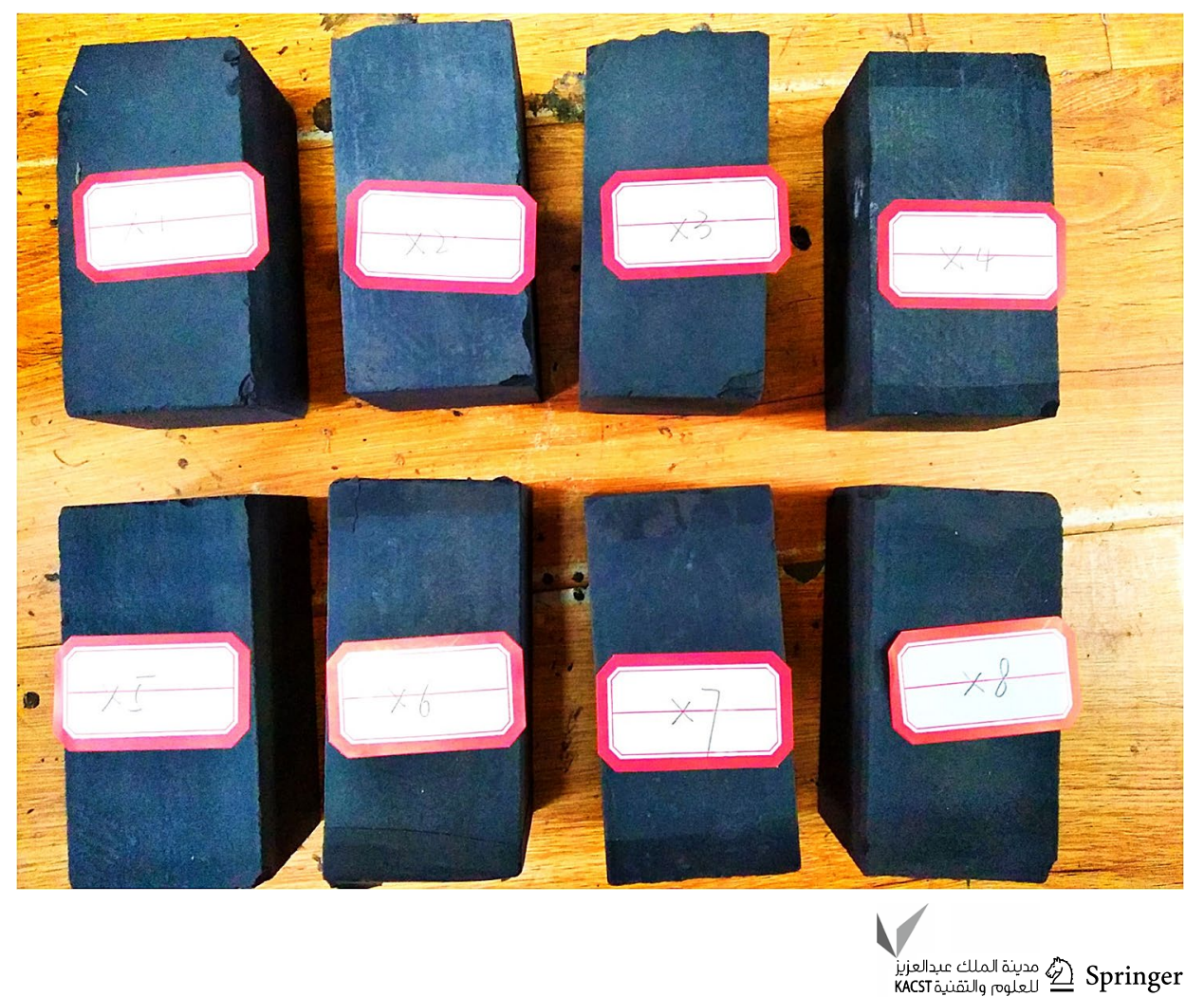




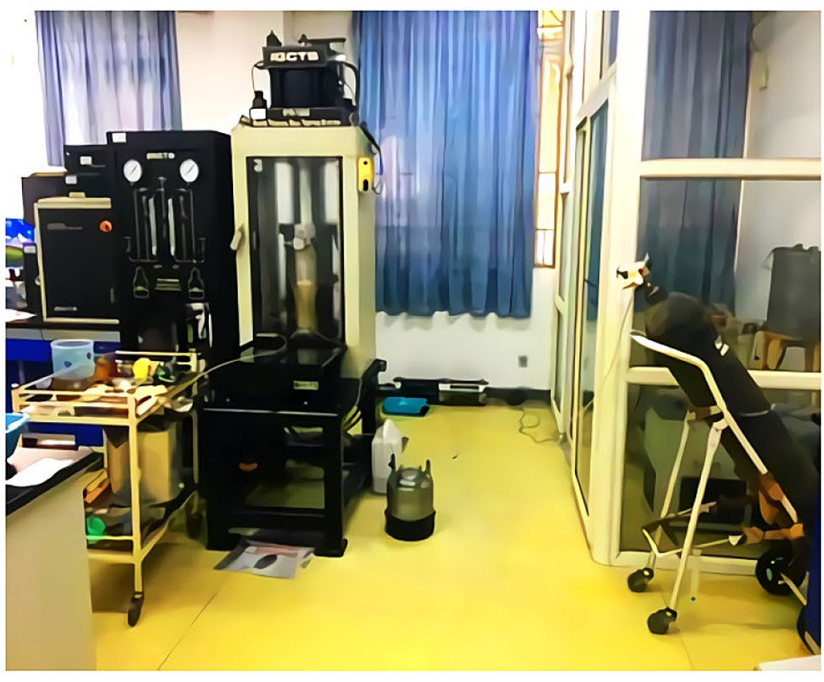

(a) Experiment platform

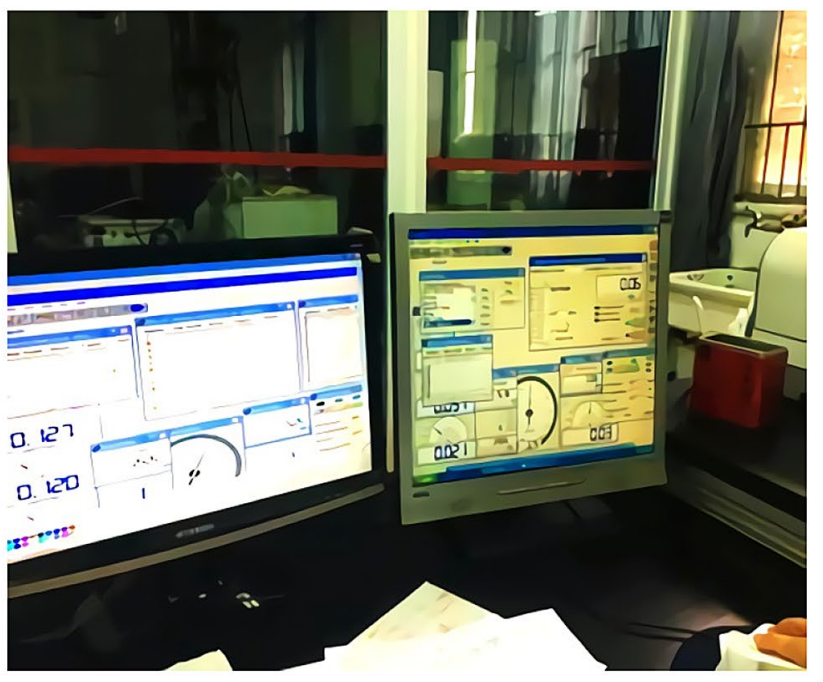

(b) Data processing terminal

Fig. 5 RTR-1000 high-temperature and high-pressure rock triaxial mechanics testing system

Table 2 Temperature and pressure parameters used in the experiment

\begin{tabular}{llllll}
\hline Group no & $\begin{array}{l}\text { Tempera- } \\
\text { ture }\left({ }^{\circ} \mathrm{C}\right)\end{array}$ & $\begin{array}{l}\text { Axial } \\
\text { unload- } \\
\text { ing rate } \\
\left(\mathrm{mm} \cdot \mathrm{s}^{-1}\right)\end{array}$ & $\begin{array}{l}\text { Initial } \\
\text { axial } \\
\text { pressure } \\
(\mathrm{MPa})\end{array}$ & $\begin{array}{l}\text { Initial } \\
\text { confining } \\
\text { pressure } \\
(\mathrm{MPa})\end{array}$ & $\begin{array}{l}\mathrm{CBM} \\
\text { pressure } \\
(\mathrm{MPa})\end{array}$ \\
\hline 1 & 40.0 & 0.01 & 30.0 & 30.0 & 3.0 \\
2 & 55.0 & & & & \\
3 & 70.0 & & & & \\
4 & 85.0 & & & & \\
5 & 100.0 & & & & \\
\hline
\end{tabular}

\section{Experimental procedure}

The following content explains in detail the specific operations of each step in the experiment. Figure 6 shows the main procedures of the experiment.

(a) Coal-rock sample installation. Coat the side of the coal-rock sample with silica gel evenly, and place it in the laboratory vent for drying treatment. After the sample is dry, use a colored pen to write the sample's corresponding number on the silica gel coating. Put the dried sample into a heat-shrinkable tube with a diameter of $65 \mathrm{~mm}$ and a height of $160 \mathrm{~mm}$. Install the heatshrinkable tube into the triaxial pressure chamber. Use a hot air gun to heat the heat-shrinkable tube to ensure that the heat-shrinkable tube is close to the sample's surface. Fix both ends of the heat-shrinkable tube with metal rings. Install a hoop extensometer in the middle of the sample. Adjust the extensometer's initial reading to an appropriate value. (b) Triaxial pressure chamber debugging. Align the triaxial pressure chamber's lower base with the upper base. Connect the inlet pipe to the inlet hole at the upper end of the pressurized piston rod. After the equipment started, slowly lower the triaxial pressure chamber's upper base until it is in full contact with the lower base. Connect the air outlet of the lower base. Close the oil inlet valve and the oil return valve, and open the communication switch between the three-axis pressure chamber and the outside. Fill the booster cylinder with oil at a constant rate. Open the oil inlet valve to fill the triaxial pressure chamber. Check whether the experimental system works.

(c) CBM adsorption. Load the confining pressure and axial pressure to $30 \mathrm{MPa}$. Open the CBM inlet valve to make the pressure display reach the predetermined value, and close the gas outlet valve at the same time to make the CBM fully adsorb. When the inlet pressure is equal to the outlet pressure, it indicates that the sample has reached the state of adsorption equilibrium and performs the follow-up operation.

(d) Run a loading experiment. Load the confining pressure and axial pressure to $30 \mathrm{MPa}$ and stabilize for $5 \mathrm{~min}$. Load the installed sample under the preset temperature condition, and observe each indicator's change during the experiment. When the sample is damaged, close the inlet valve, open the outlet valve, stop the experiment, and collect and sort out the experiment's relevant data.

(e) Post-experiment processing. After completing the experiment, take out the coal-rock sample, and observe the coal-rock sample's shape after failure. 
Fig. 6 The main procedures of the experiments

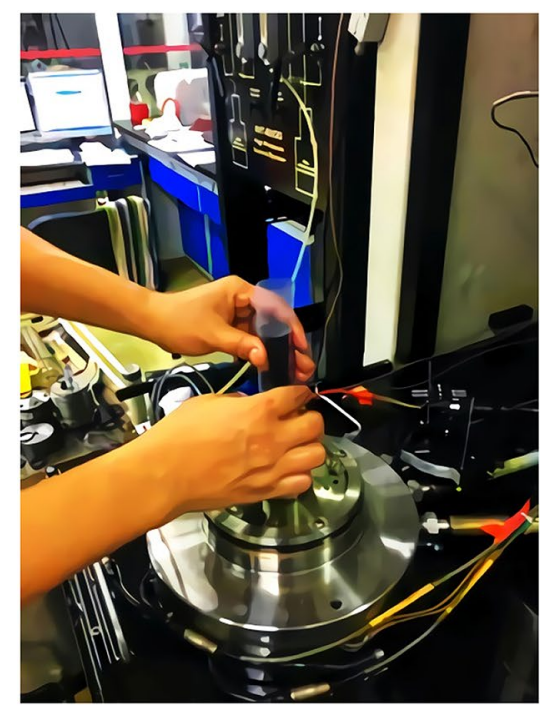

(a) Coal-rock sample installation

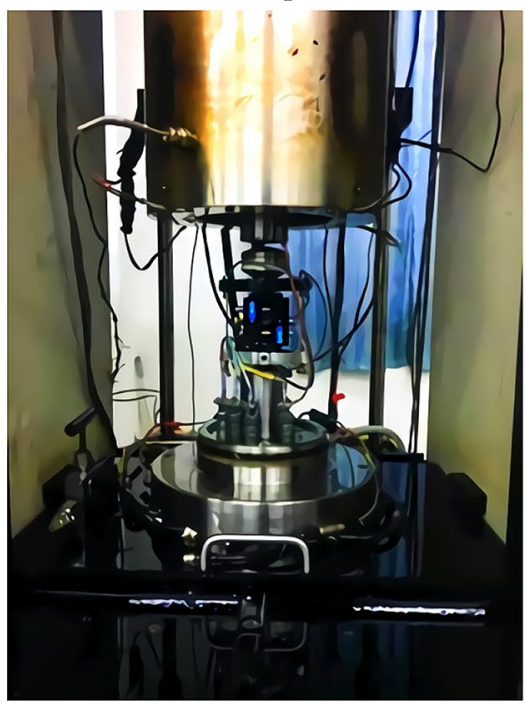

(c) CBM adsorption

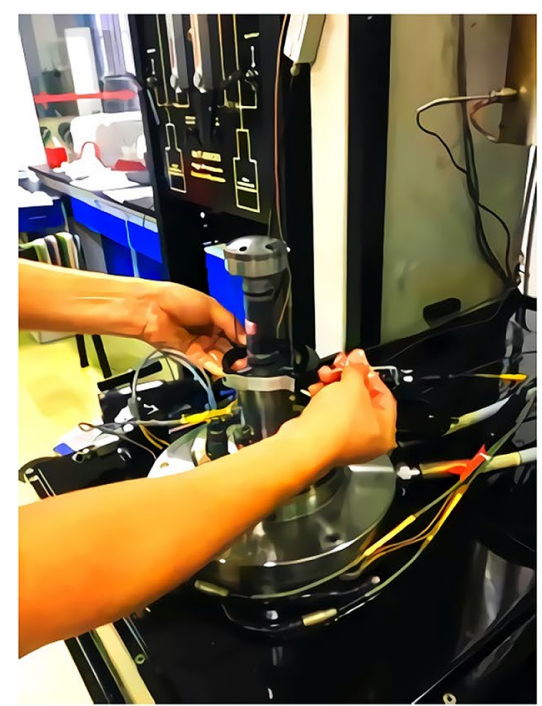

(b) Triaxial pressure chamber debugging

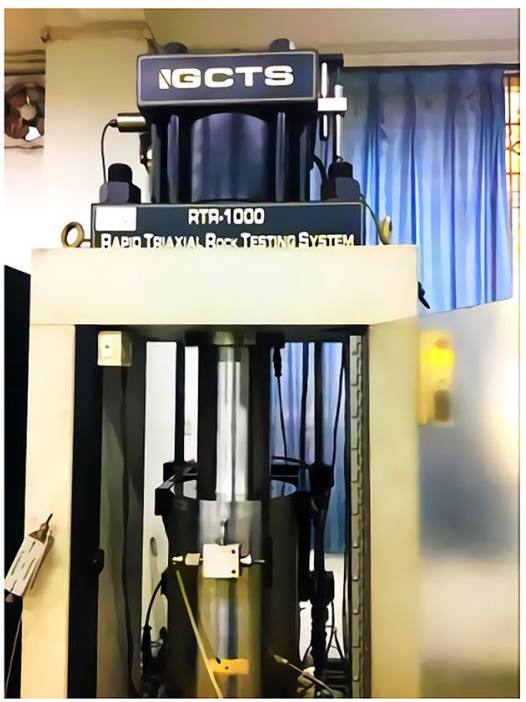

(d) Run a loading experiment

\section{Analysis of experimental results}

\section{Analysis of stress-strain curve}

We conducted triaxial loading experiments on coal-rock samples under different loading temperature conditions. We obtained the change characteristics of the stress-strain curve of the coal-rock samples under different temperature conditions. As explained in the experimental method, when we experiment, the loading temperature of each group of coalrock samples is different, but the pressure conditions are the same. Figure 7 shows the stress-strain curves of each group of coal-rock samples obtained in the experiment under different temperature conditions. Table 3 shows the test results of stress and strain when the coal-rock samples break.

Suppose the average stress of each group of coal-rock samples as the reference value. In that case, it can be seen from the experimental results shown in Fig. 7 and Table 3 that the higher the temperature loaded during the experiment, the lower the stress value of the coal-rock sample when it breaks. From the perspective of engineering applications, the higher the surrounding rock's temperature, the lower the stress value when the borehole breaks. Under the condition of constant bottom hole pressure, the higher the temperature of the surrounding rock of CBM wells, the more likely the coal seam borehole will collapse.

\section{Analysis of axial, radial, and volumetric strain}

To analyze the strain changes of coal-rock samples under different temperature conditions, we compared the relationship between the axial, radial, and volume strains under five temperature conditions through experimental tests. Figure 8 shows the strain results of coal-rock samples under different

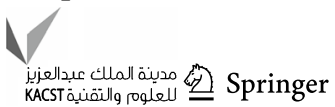



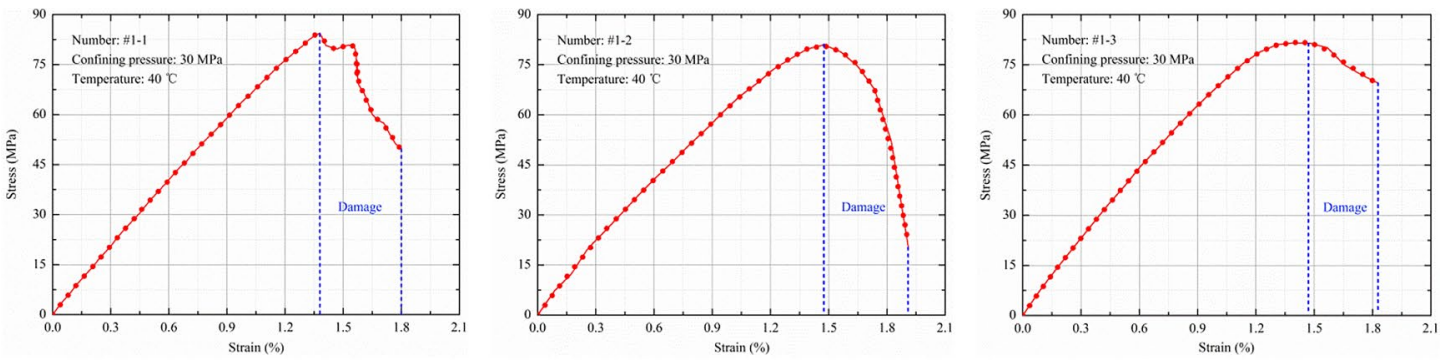

(a) Stress-strain curve of the first group of coal-rock samples at $40{ }^{\circ} \mathrm{C}$
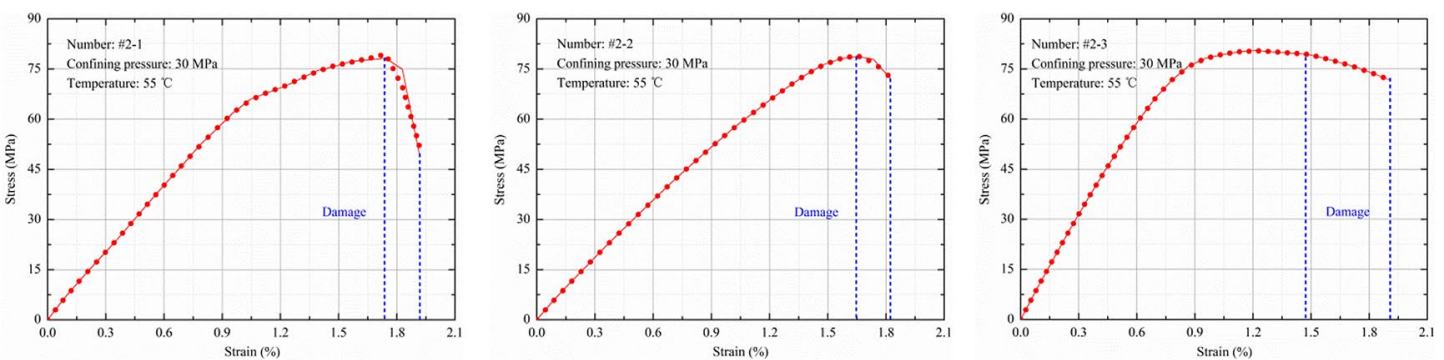

(b) Stress-strain curve of the second group of coal-rock samples at $55^{\circ} \mathrm{C}$
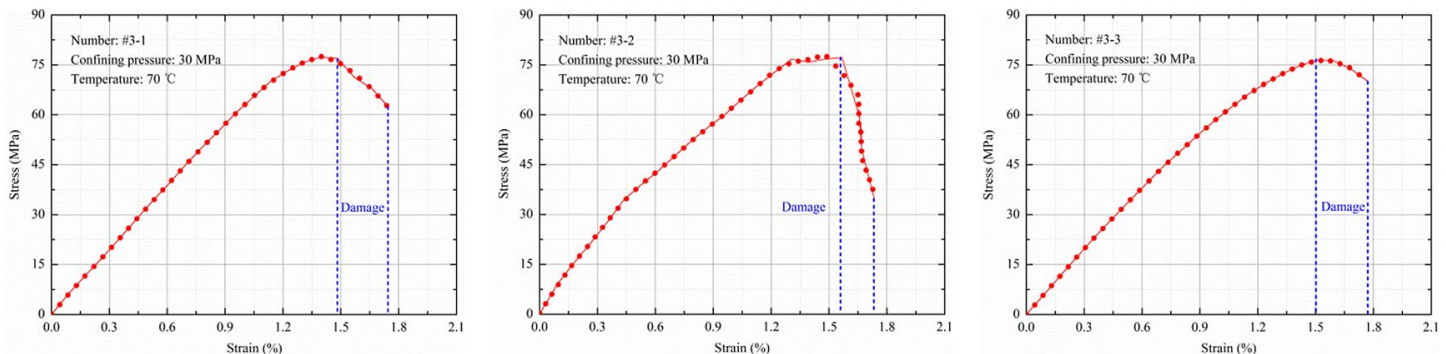

(c) Stress-strain curve of the third group of coal-rock samples at $70{ }^{\circ} \mathrm{C}$
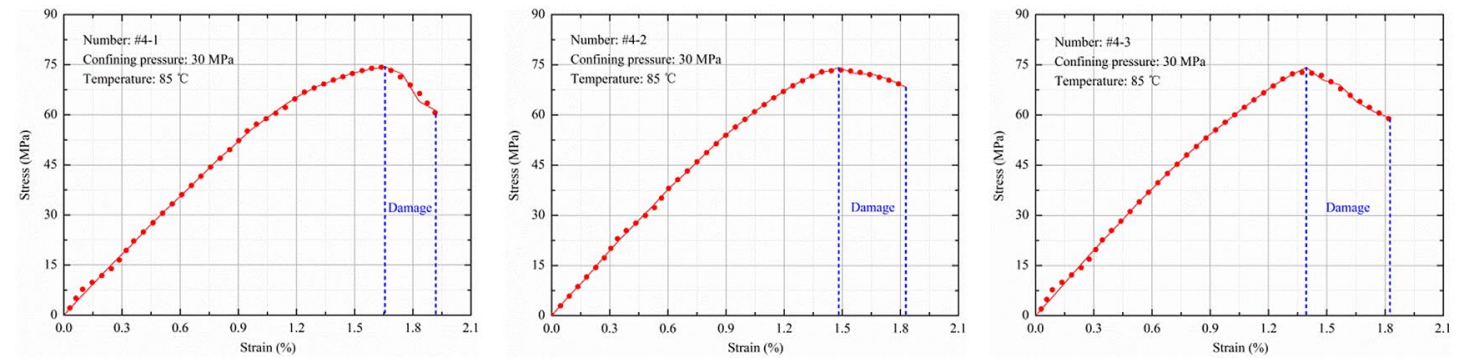

(d) Stress-strain curve of the fourth group of coal-rock samples at $85^{\circ} \mathrm{C}$
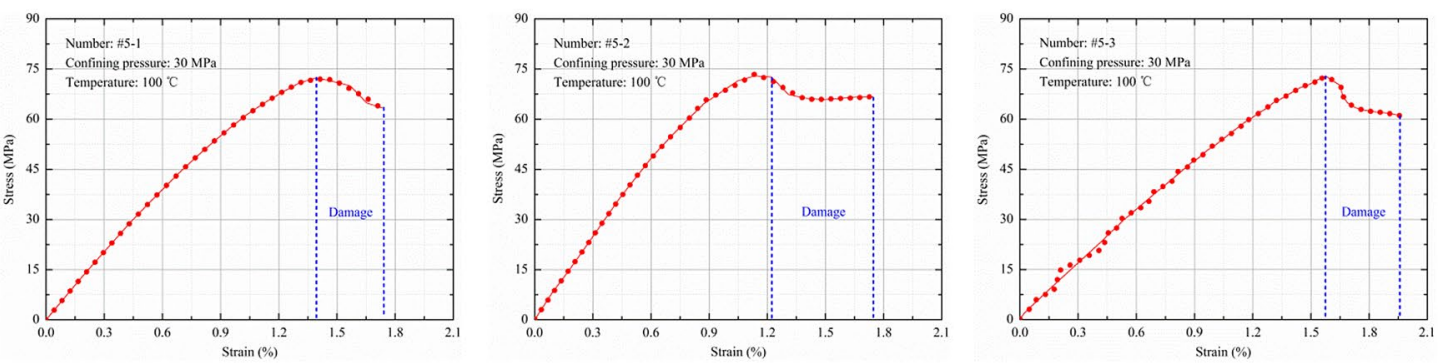

(e) Stress-strain curve of the fifth group of coal-rocks samples at $100{ }^{\circ} \mathrm{C}$

Fig. 7 Stress-strain curves of coal-rock samples under different temperature conditions 
Table 3 Stress and strain test results when the coal sample breaks

\begin{tabular}{llllll}
\hline Group no & Sample no & $\begin{array}{l}\text { Stress } \\
\text { (MPa) }\end{array}$ & $\begin{array}{l}\text { Average } \\
\text { stress } \\
(\mathrm{MPa})\end{array}$ & Strain (\%) & $\begin{array}{l}\text { Average } \\
\text { strain } \\
(\%)\end{array}$ \\
\hline 1 & $\# 1-1$ & 80.81 & 81.09 & 1.38 & 1.47 \\
& $\# 1-2$ & 80.95 & & 1.46 & \\
& $\# 1-3$ & 81.52 & & 1.47 & \\
& $\# 2-1$ & 78.23 & 78.44 & 1.74 & 1.62 \\
& $\# 2-2$ & 78.78 & & 1.65 & \\
& $\# 2-3$ & 78.30 & & 1.48 & \\
& $\# 3-1$ & 76.94 & 76.69 & 1.48 & 1.52 \\
& $\# 3-2$ & 76.73 & & 1.57 & \\
4 & $\# 3-3$ & 76.41 & & 1.50 & \\
& $\# 4-1$ & 74.36 & 74.21 & 1.66 & 1.51 \\
& $\# 4-2$ & 74.11 & & 1.48 & \\
& $\# 4-3$ & 74.17 & & 1.39 & \\
& $\# 5-1$ & 72.38 & 72.71 & 1.39 & 1.40 \\
& $\# 5-2$ & 72.92 & & 1.22 & \\
& $\# 5-3$ & 72.82 & & 1.58 & \\
\hline
\end{tabular}

temperature conditions. Table 4 shows the mechanical test results when the coal-rock sample reaches the peak strength.

The experimental results shown in Fig. 8 and Table 4 show that the axial, radial and volumetric strains of the coal-rock samples at peak strength will vary with the experimental loading temperature. However, they do not show an apparent linear relationship. On the other hand, when the coal-rock sample reaches its peak strength, the higher the temperature loaded in the experiment, the higher the proportion of plastic deformation in its entire deformation stage. From the perspective of engineering application, under constant bottom hole pressure, the higher the temperature of the surrounding rock of a CBM well, the more likely it is to produce irreversible deformation of the borehole, and the easier it is to cause complex downhole conditions.

\section{Analysis of mechanical parameter}

During the experiment, the relationship curves between the various mechanical parameters of the coal-rock sample and the experimental loading temperature are shown in Fig. 9. The functional relationship between the two are shown in Table 5.

It can see from the experimental results shown in Fig. 9 that the compressive strength, elastic modulus, and main crack length of the coal-rock sample will decrease with increasing temperature. In contrast, the Poisson's ratio and the primary fracture angle will decrease with increasing temperature. Moreover, the numerical fitting results shown in Table 5 reflect a particular linear relationship between the

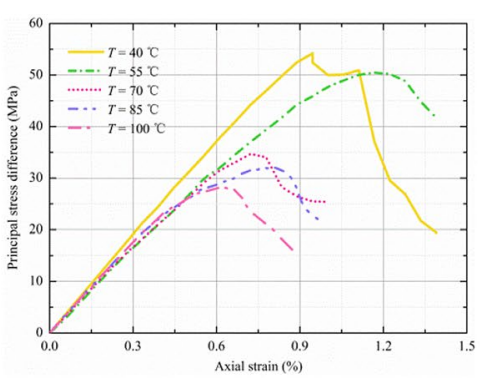

(a) Axial strain

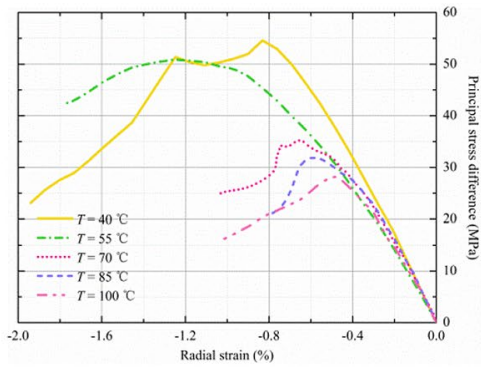

(b) Radial strain

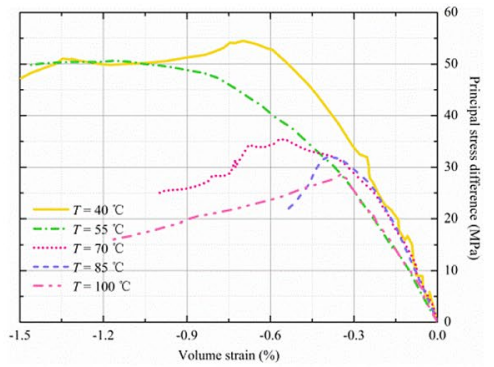

(c) Volumetric strain

Fig. 8 Strain test results of coal-rock samples under different temperature conditions

Table 4 Mechanical test results when the coal-rock sample reaches peak strength

\begin{tabular}{lllllll}
\hline $\begin{array}{l}\text { Temperature } \\
\left({ }^{\circ} \mathrm{C}\right)(\%)\end{array}$ & $\begin{array}{l}\text { Principal stress dif- } \\
\text { ference }(\mathrm{MPa})\end{array}$ & Axialstrain (\%) & Radial strain $(\%)$ & $\begin{array}{l}\text { Volumetric } \\
\text { strain }(\%)\end{array}$ & $\begin{array}{l}\text { Proportion of plastic } \\
\text { deformation }\end{array}$ & $\begin{array}{l}\text { Proportion of } \\
\text { elastic deforma- } \\
\text { tion }(\%)\end{array}$ \\
\hline 40 & 54.5 & 0.95 & -0.82 & -0.56 & 7.8 & 92.2 \\
55 & 50.6 & 1.18 & -1.14 & -0.68 & 19.3 & 80.7 \\
70 & 34.3 & 0.79 & -0.65 & -0.26 & 21.1 & 78.9 \\
85 & 32.1 & 0.80 & -0.62 & -0.27 & 23.2 & 76.8 \\
100 & 28.3 & 0.61 & -0.46 & -0.29 & 25.7 & 74.3 \\
\hline
\end{tabular}




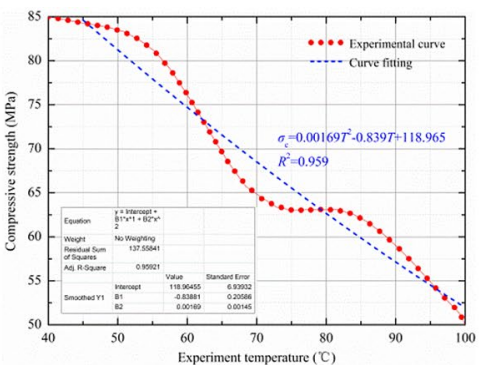

(a) Compressive strength

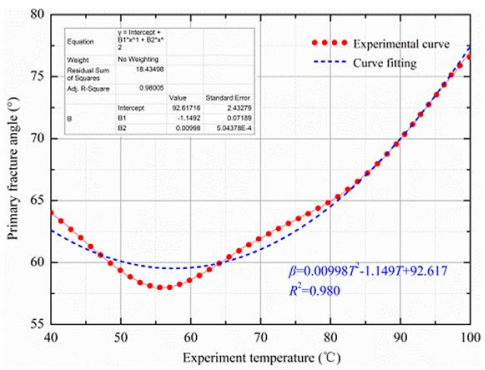

(d) Primary fracture angle

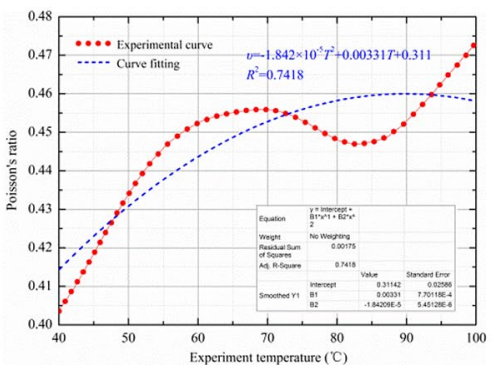

(b) Poisson's ratio

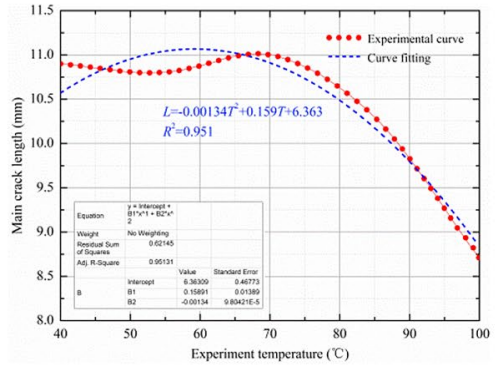

(e) Main crack length

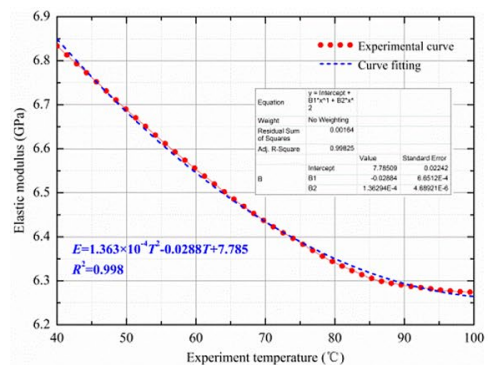

(c) Elastic modulus

Fig. 9 The relationship curve between mechanical parameters of coal-rock sample and temperature

Table 5 Function relationship between mechanical parameters of coal-rock sample and temperature

\begin{tabular}{lll}
\hline Parameter & Function relationship & Relativity \\
\hline Compressive strength & $\sigma_{c}=0.00169 T^{2}-0.839 T+118.965$ & 0.959 \\
Poisson's ratio & $v=-1.842 \times 10^{-5} T^{2}+0.00331 T+0.311$ & 0.742 \\
Elastic modulus & $E=1.363 \times 10^{-4} T^{2}-0.0288 T+7.785$ & 0.998 \\
Primary fracture angle & $\beta=0.00998 T^{2}-1.149 T+92.617$ & 0.980 \\
Main crack length & $L=-0.00134 T^{2}+0.159 T+6.363$ & 0.951 \\
\hline
\end{tabular}

above-mentioned mechanical parameters of the coal-rock sample and temperature.

\section{Conclusion}

In this paper, we select coal-rock samples from the Linfen CBM exploitation area in Shanxi Province as the experimental samples, aiming at exploring the change characteristics of the mechanical properties of coal-rock under varying temperature conditions. We conducted comprehensive experimental tests on the stress-strain curve, axial strain, radial strain, and volume strain of coal-rock and obtained the corresponding change law. The conclusions we got are as follows:

(1) Under the same pressure conditions, if the temperature of the coal-rock is higher, the stress value when it fails is lower. When the exploitation depth of CBM expands to deeper layers, this phenomenon will inevitably become more pronounced as the formation temperature rises and the fluid circulation time in the wellbore increases.

(2) In the process of reaching the peak strength, if the temperature of the coal-rock is higher, the proportion of plastic deformation in the entire deformation stage of the coal-rock is higher. This shows that if coal-rock are deformed in a high-temperature environment, the less likely it is to return to its original shape, and the easier it is to cause the collapse of the wellbore.

(3) The compressive strength, elastic modulus and main crack length of coal-rock are no longer a fixed value under the influence of temperature, but will decrease with the increase of temperature. This rule needs to be taken into consideration when conducting wellbore stability analysis.

(4) With the change of temperature, the Poisson's ratio and primary fracture angle of coal-rock are no longer a fixed value but will increase with temperature. This change rule also needs to be considered in the wellbore stability analysis. 
The above conclusions reflect that if we want to exploit deep-seated CBM in the Linfen CBM exploitation area, we should consider corresponding measures to limit the heat exchange between the fluid in the wellbore and the coalrock. This measure is more conducive to the exploitation of deep CBM in the Linfen CBM exploitation area.

Funding The authors thank the financial supports from the National Natural Science Foundation of China (No. 51274168), the National Key R\&D Program of China (No. 2018YFC0310202), and the Southwest Petroleum University Graduate Research and Innovation Fund Key Program (No. 2020CXZD30). Special thanks to Dr. Zhan Jiaju, the State Key Laboratory of Oil and Gas Reservoir Geology and Exploitation, Southwest Petroleum University, for providing the corresponding equipment and ideas for the experimental test.

\section{Declarations}

Conflict of interest The authors declare that they have no known competing financial interests or personal relationships that could have influenced the work reported in this paper.

Open Access This article is licensed under a Creative Commons Attribution 4.0 International License, which permits use, sharing, adaptation, distribution and reproduction in any medium or format, as long as you give appropriate credit to the original author(s) and the source, provide a link to the Creative Commons licence, and indicate if changes were made. The images or other third party material in this article are included in the article's Creative Commons licence, unless indicated otherwise in a credit line to the material. If material is not included in the article's Creative Commons licence and your intended use is not permitted by statutory regulation or exceeds the permitted use, you will need to obtain permission directly from the copyright holder. To view a copy of this licence, visit http://creativecommons.org/licenses/by/4.0/.

\section{References}

Cheng RD, Chen HY, Xian XF, Wang GC (1998) Experiments on the affection of temperature on permeability coefficient of coal samples. Min Saf Environ Protect 1:13-16

Jiang B, Qing Y, Jin FL (1997) Coal deformation test under high temperature and confining pressure. J China Coal Soc 22:80-83

Li HW, Wang LG, Niu FM, Kang JC, Zhang CH (2016) Experimental study on the structure crack damage of the coal samples via the abrupt temperature-changing cycles. J Saf Environ 16:40-43

Li X, Zhang J, Tang X, Mao GZ, Wang PG (2020) Study on wellbore temperature of riserless mud recovery system by CFD approach and numerical calculation. Petroleum 6:163-169
Ma ZG, Mao XB, Li YS, Chen ZQ, Zhu P (2005) The lab test of the influence of temperature to coal mechanics characteristic. J Min Saf Eng 3:46-48

Mahanta B, Ranjith PG, Vishal V, Singh TN (2020) Temperatureinduced deformational responses and microstructural alteration of sandstone. J Pet Sci Eng 192:107239

Ranjith PG, Viete DR, Chen BJ, Perera MS (2012) Transformation plasticity and the effect of temperature on the mechanical behaviour of Hawkesbury sandstone at atmospheric pressure. Eng Geol 151:120-127

Rao QH, Wang Z, Xie HF, Xie Q (2007) Experimental study of mechanical properties of sandstone at high temperature. J Cent South Univ Technol 14:478-483

Shen YJ, Zhang YL, Gao F, Yang GS, Lai XP (2018) Influence of temperature on the microstructure deterioration of sandstone. Energies 11(7): 1753

Sirdesai NN, Singh TN, Ranjith PG, Singh R (2017) Effect of varied durations of thermal treatment on the tensile strength of red sandstone. Rock Mech Rock Eng 50:205-213

Tripathi A, Gupta N, Singh AK, Mohanty SP, Rai N (2021) Pain a effects of elevated temperatures on the microstructural, physicomechanical and elastic properties of Barakar sandstone: a study from one of the world's largest underground coalmine fire region, Jharia, India. Rock Mech Rock Eng 54:1293-1314

Wang K, Zhang GS, Li ZX, Liang K, Huang JL (2020) Current status and trends of coalbed methane exploration \& development in Shanxi Province. China Coalbed Mathane 17(6):39-43

Wei JP, Sun LT, Wang DK, Li B, Peng M, Liu SM (2017) Change law of permeability of coal under temperature impact and the mechanism of increasing permeability. J China Coal Soc 42:1921-1925

Xu J, Zhang DD, Peng SJ, Nie W, Wang L, Chen YL (2011) Experimental research on impact of temperature on seepage characteristics of coal containing methane under triaxial stress. Chin J Rock Mechan Eng 30:1849-1854

Yan M, Zhang YZ, Lin HF, Li JL, Qin L (2020) Effect on liquid nitrogen impregnation of pore damage characteristics of coal at different temperatures. J China Coal Soc 45:2813-2823

Yu YJ, Zhang H, Zhang CH, Hao Z, Wang LG (2013) Effects of temperature and stress on permeability of standard coal briquette specimen. J China Coal Soc 38:936-941

Zhang J, Li X, Tang X, Luo W (2019) Establishment and analysis of temperature field of riserless mud recovery system. Oil Gas Sci Technol 74:19-27

Publisher's Note Springer Nature remains neutral with regard to jurisdictional claims in published maps and institutional affiliations. 